\title{
Removal of \\ Densiron-68 with a 23-gauge transconjunctival vitrectomy system
}

MR Romano, C Groenwald, R Das, T Stappler, D Wong and $\mathrm{H}$ Heimann

\begin{abstract}
Purpose To report a new approach for removal of Densiron-68 via pars plana with a 23-gauge transconjunctival sutureless vitrectomy system (TSVS).

Methods Prospective, interventional case series. Ten eyes ( 4 phakic, 5 pseudophakic, 1 aphakic) of 10 patients underwent Densiron$68(1480 \mathrm{mPa}$ viscosity and $1.06 \mathrm{~g} / \mathrm{ml} \mathrm{specific}$ gravity) removal via pars plana with a suction pressure of $600-\mathrm{mmHg}$ vacuum through a short 23-gauge silicon cannula.

Results Densiron-68 was completely removed from all eyes. Retinal reattachment was achieved in all cases. The intraocular pressure was 20.9 (SD 3.5) $\mathrm{mmHg}$ at baseline, 12.2 (SD 4) $\mathrm{mmHg}$ at day 1 postoperatively, and 13.6 (SD 2.9), 15.4 (SD 2.5), and 16 (SD 1.8) $\mathrm{mmHg}$ after 1 week, 1 month, and 3 months, respectively. Five eyes needed suture of at least one sclerotomy. Postoperative hypotony $(\leqslant 8 \mathrm{mmHg})$ was seen in 2 out of 10 eyes (20\%). No additional postoperative procedure was necessary.

Conclusions Active removal of Densiron-68 with a 23-gauge short cannula is a simple, innovative, and safe technique that can help reduce surgical trauma.
\end{abstract}

Eye (2009) 23, 715-717; doi:10.1038/eye.2008.396; published online 16 January 2009

Keywords: 23-gauge transconjunctival sutureless vitrectomy; removal of heavy silicon oil; Densiron-68

\section{Introduction}

Densiron-68 (Fluoron, Neu-Ulm, Germany) is an intraocular tamponade used for inferior retinal tears owing to its specific gravity being greater than water. Over the past few years it has gained increasing popularity, thanks to more and more encouraging anatomical and functional results. ${ }^{1,2}$ The drawback of the use of Densiron-68 may be related to the difficulty of its removal. The gravity acting on the bubble, the force of adhesion between Densiron-68 and the retina, and its viscosity may cause special problems during its removal. ${ }^{3}$ We report a 23-gauge transconjunctival technique for active removal of Densiron-68 through a short 23-gauge cannula.

Patients and methods

Ten consecutive eyes underwent active removal of Densiron-68 via pars plana, using a 23-gauge transconjunctival sutureless vitrectomy system (TSVS). Densiron-68 was removed 102 (SD 48) days after the initial surgery for RRDs with inferior retinal breaks (between 4 and 8 clock hours). The duration of critical time period for removal of oil differs from case to case. We removed Densiron-68 according to the retina status and clinically significant amount of emulsification.

Complete ophthalmic examinations, including best-corrected visual acuity (BCVA), intraocular pressure (IOP), and indirect ophthalmoscopy, were scheduled at baseline and at 1 day, 1 week, 1 and 3 months after the removal of Densiron-68.

\section{Surgical technique}

The surgical procedure was based on a 23-gauge TSVS using a one-step system (Alcon Laboratories Inc., Fort Worth, TX, USA). The conjunctiva was displaced and $30^{\circ}$-angled incisions were made with a combined 23-gauge blade-trocar system to obtain tunnels parallel to the corneoscleral limbus. The IOP was
St Paul's Eye Unit, Royal Liverpool University Hospital, Liverpool, UK

Correspondence: MR Romano, St Paul's Eye Unit, Royal Liverpool University Hospital, Prescot Street, Liverpool L7 8XP, UK Tel: + 44796019 2539; Fax: + 441517065905 E-mail: romanomario@ email.it

Received: 2 August 2008 Accepted in revised form: 24 November 2008 Published online: 16 January 2009 
maintained at $40 \mathrm{mmHg}$ using the vented gas forced infusion of the ACCURUS system. Densiron-68 (1480 $\mathrm{mPa}$ viscosity) was removed with suction of $600-\mathrm{mmHg}$ vacuum through a short 23-gauge silicon cannula (PolyTip ${ }^{\mathbb{R}}$ VFI Cannula, $0.6 \mathrm{~mm}(23 \mathrm{G}) \times 7.0 \mathrm{~mm}$, MedOne Surgical, Sarasota, FL, USA) (Figure 1).

The main endpoints of our study were rate of complete removal of Densiron-68 and rate of anatomical success with retinal reattachment. We also analyzed the changes in IOP and the occurrence of complications.

\section{Results}

Ten eyes (4 phakic, 5 pseudophakic, and 1 aphakic) of 10 patients ( 5 males and 5 females) with a mean age of 58.5

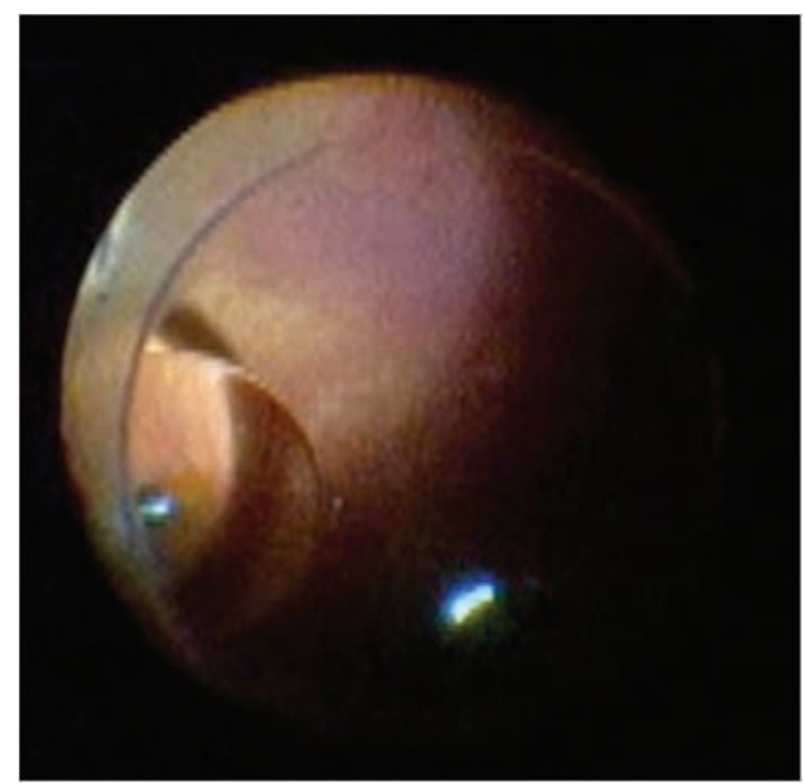

Figure 1 Densiron-68 bubble levitated by the short 23-gauge cannula in the middle of the vitreous cavity. years (SD 8.4) underwent active removal of Densiron-68 through a 23-gauge TSVS. No intraoperative complications were reported. Suture placement was not necessary in any of the sclerotomies in 5 out of 10 eyes. Three eyes needed suture of $1 / 3$ and two eyes of $2 / 3$ of the sclerotomies. Densiron-68 was completely removed from all eyes, with no clinically significant residual oil in the vitreous cavity seen at follow-up examinations (Table 1). Multiple small droplets of Densiron-68 may remain in the posterior segment after removal of the main body of silicon oil. These residual droplets can be easily removed with a 23-gauge flute needle with passive aspiration.

The time taken to remove similar volumes of Densiron68 was approximately the same with a short 23 -gauge cannula as it was with a short 20-gauge cannula.

Following tamponade removal, retinal reattachment was achieved in all cases (100\%). Mean BCVA improved from 0.70 (SD 0.51) to 0.48 (SD 0.9) logMAR.

The IOP was 20.9 (SD 3.5) $\mathrm{mmHg}$ at baseline, 12.2 (SD 4) $\mathrm{mmHg}$ at 1 day, and 13.6 (SD 2.9), 15.4 (SD 2.5), and 16 (SD 1.8) $\mathrm{mmHg}$ at 1 week, 1 and 3 months, respectively (Table 1).

Anterior chamber shallowing occurred in 1 out of 10 eyes $(10 \%)$. Localized bleb formation was not seen. Three out of five phakic patients developed cataract during the follow-up. Postoperative hypotony $(\leqslant 8 \mathrm{mmHg})$ was seen in 2 out of 10 eyes $(20 \%)$, but resolved spontaneously within 1 week.

\section{Discussion}

The conventional way of removing heavy silicon oil with a $0.90 \mathrm{~mm}(20 \mathrm{G}) \times 28 \mathrm{~mm}$ cannula reaching the lowest part of the vitreous cavity is associated with risk of complications mainly related to the larger scleral openings (entry site tears) and to the high suction

Table 1 Demographics and outcomes of study patients

\begin{tabular}{|c|c|c|c|c|c|c|c|c|c|c|}
\hline \multirow[t]{2}{*}{ Patient no. } & \multirow[t]{2}{*}{ Age } & \multirow[t]{2}{*}{ Sex } & \multirow[t]{2}{*}{ Eye } & \multirow[t]{2}{*}{ Lens status } & \multicolumn{5}{|c|}{ Intraocular pressure } & \multirow[t]{2}{*}{ Sclerotomy needed suture } \\
\hline & & & & & Baseline & 1 day & 1 week & 1 month & 3 month & \\
\hline 1 & 53 & Male & Right & Phakic & 20 & 14 & 14 & 14 & 16 & $2 / 3$ \\
\hline 2 & 62 & Male & Right & Phakic & 16 & 12 & 10 & 12 & 12 & 0 \\
\hline 3 & 70 & Female & Left & Pseudophakic & 22 & 10 & 10 & 12 & 16 & 0 \\
\hline 4 & 55 & Male & Left & Phakic & 25 & 12 & 16 & 16 & 18 & $1 / 3$ \\
\hline 5 & 70 & Male & Right & Pseudophakic & 18 & 8 & 14 & 16 & 16 & 0 \\
\hline 6 & 45 & Female & Left & Pseudophakic & 26 & 22 & 20 & 20 & 18 & $2 / 3$ \\
\hline 7 & 48 & Female & Right & Pseudophakic & 20 & 10 & 14 & 14 & 14 & 0 \\
\hline 8 & 58 & Female & Right & Aphakic & 16 & 8 & 12 & 16 & 16 & $1 / 3$ \\
\hline 9 & 60 & Male & Right & Pseudophakic & 22 & 12 & 12 & 16 & 16 & $1 / 3$ \\
\hline 10 & 64 & Female & Right & Phakic & 24 & 14 & 14 & 18 & 18 & 0 \\
\hline
\end{tabular}


pressure applied close to the retina through a relatively large bore opening. ${ }^{3,4}$ If the needle is momentarily emptied of the viscous oil, the eye might suddenly collapse and the needle tip could damage the retina.

Stappler et $a l^{5}$ have recently proved that the removal of Densiron-68 is possible using a short 20-gauge steel needle. A combination of forces, such as the interfacial tension between the cannula and the oil, as well as the phenomenon of tubeless siphoning, makes it feasible and reduces the risk of iatrogenic damage.

We report that it is also possible to remove Densiron-68 using a 23-gauge cannula of only $7.0 \mathrm{~mm}$ in length using $600 \mathrm{mmHg}$ of suction pressure. Densiron-68 is made of polymers and behaves as non-Newtonian fluids. When such non-Newtonian fluids are forced through a narrow opening, the three-dimensional structure of the molecules unfolds, thereby storing up energy in the process. ${ }^{5}$ The key point of this technique is to not lose the contact between the tip of the short cannula and the oil bubble. The only problem is related to the postoperative leaking of sclerotomies. After removal of silicon oil, the vitreous body base is mostly contracted and compressed; hence the remaining peripheral vitreous cannot seal the sclerotomies as happens for macular surgery, when a broad rim of peripheral vitreous is not removed. ${ }^{6}$ To prevent such postoperative hypotony, we prefer to put a single transconjunctival suture on the sclerotomy in case of leakage after the removal of the trocar.

In conclusion, active removal of Densiron-68 with a 23-gauge short cannula is a simple, innovative, and safe technique, which can help reduce surgical trauma. It can be performed in phakic, pseudophakic, and aphakic eyes. Controlled studies with larger series are warranted.

\section{Acknowledgements}

The authors indicate no financial support or financial conflict of interest. MRR and CGR were involved in conception, design of the study and data analysis; RD and, CGR were involved in collection and management of the data; CGR and MRR were involved in the provision of patients; MRR, TS and $\mathrm{HH}$ were involved in the preparation of the manuscript; DW and $\mathrm{HH}$ were involved in the review and approval of the manuscript.

\section{References}

1 Romano MR, Stappler T, Marticorena J, Groenewald C, Pearce I, Gibran SK et al. Primary vitrectomy with Densiron-68 for rhegmatogenous retinal detachment. Graefes Arch Clin Exp Ophthalmol 2008; 246(11): 1541-1546 [e-pub ahead of print].

2 Heimann H, Stappler T, Wong D. Heavy tamponade 1: a review of indications, use, and complications. Eye 2008; 22(10): 1342-1359.

3 Cheung BT, Lai TY, Yuen CY, Lai WW, Tsang CW, Lam DS Results of high-density silicon oil as a tamponade agent in macular hole retinal detachment in patients with high myopia. Br J Ophthalmol 2007; 91: 719-721.

4 Wolf S, Schön V, Meier P, Wiedemann P. Silicon oil-RMN3 mixture ('heavy silicon oil') as internal tamponade for complicated retinal detachment. Retina 2003; 23: 335-342.

5 Stappler T, Williams R, Gibran SK, Liazos E, Wong D. A guide to the removal of heavy silicon oil. $\mathrm{Br} J$ Ophthalmol 2008; 92: 844-847.

6 Faia LJ, McCannel CA, Pulido JS et al. Outcomes following 25-gauge vitrectomies. Eye 2008; 22: 1024-1028. 